Ciência e Natura, v. 36 Part 2 2015, p. 291-296

\title{
A Framework for Improving Web 2.0 Interaction Design
}

\author{
Mohammad Hajarian ${ }^{*}$
}

${ }^{1}$ Young Researchers and Elite Club, Karaj Branch, Islamic Azad University, Karaj, Iran

\begin{abstract}
Interaction design of websites has been changed during last decade, yet principles of interaction design and frameworks seem not to be updated based on the new technology and findings. Moreover most of the web developers are just trying to copy other famous companies' works, because they do not have any idea what standards they have to follow, and this is not because there is not any frameworks and standards but it is because these frameworks do not meet new technology requirements. Although most of the research on interaction design did not consider elements such as Ajax pages and different type of device's screen size such as tablets and phones (and they influence on web page design), in this research author has reviewed different principles of interaction design in different studies and based on these studies and recent changes in technology, suggested a new framework. Furthermore two round study was performed on a social network website, one before implementing this framework and the other one after implementing it. Additionally findings were evaluated to show that by implementing this framework in web design not only developers, but users will benefit from it.
\end{abstract}

Keywords: Interaction design, web site, web 2.0, framework.

\footnotetext{
*m.hajarian@kiau.ac.ir
} 


\section{Introduction}

$\mathrm{I}$ nteraction design is playing very important role in design of websites. In the era of web 2.0 it is called user interface, where users interact with the system, it does not matter how advanced and sophisticated is the code that has been wrote behind the website, it is the user interface that makes users decide about a product. Web developers are always confused about what is so called "standard design" and they always wants to know how should design a webpage (e.g. how should they design an online store or a social network or a personal website user interface?). To answer these questions developers usually try to see other developers works and try to make "something like" another website. Although this approach works and customers are usually happy but this might not address all the development of specific website requirements, additionally this might make the new website look like another existing website and questions the originality of the design. Hence web developers require a guideline to develop modern and effective websites, websites that users enjoy working with. To have this guideline for developers author has reviewed different papers of interaction design and introduced a framework for web developers to implement it while developing websites' user interface.

\section{Literature review on interaction design}

While performing literature review by author, the lack of implementing new technology to improve the interaction design was obvious. Most of the recent publications about web site interaction design are still using the main ideas of jakob Nielsen 1994 articles. Although jakob nielsen's works and principles (Nielsen,1994) (Preece and Yvonne, 2015) without a doubt are the most inspiring principles used in interaction design, new changes in technology and web 2.0 needs more modern solutions to be applied by developers. In the proposed framework
Nielsen's principles was managed to gather in some comprehensive questions.

On the other hand in the design stage, web developers often use site map and story boards to have a better idea what they are going to design and the requirements (Newman and James, 2000). This can be done using sketching on the paper or using a software called DENIM which let developers scratch their webpage design, site map and story board and easily interact with the system. However the problem of this system is that the proposed software is too old that it does not address problems such as different monitor sizes and devices in addition to Ajax webpage design principles. Which was addressed in the author's proposed framework.

Moreover another research suggests that good webpage design is combination of lots of graphics and advertisement from famous companies (Ivory and Rodrick, 2005). This concept of good webpage design has been changed over last decade and now that researcher is in 2015, most of the websites use less graphic pictures and try to avoid advertisement. Hence it seems looking to the trends and what other websites interaction design is, has always been an important factor to define a good interaction design. Furthermore every product that will be used by someone should be an easy and pleasant product and in new web 2.0 designs, developers mostly use Ajax pages and as it is suggested, it is important to know how to use Ajax pages in design (Garrett,2005). Hence in the proposed framework Ajax pages in addition to other webpage design principles were considered.

\section{First study}

User profiling is one of the best methods to have a good understanding about the end users of a websites. By performing user profiling, developer can have better idea how they have to develop a system that can be pleasant to be used by its users. This is where developers learn who the users are and what are their requirements. Having a clear idea about the end users will help developers to produce better interaction design. 
In this study based on Creswell quantitative method of research (Creswell,2002) an online survey was conducted. Researcher using an online survey has asked from 506 members of gohardasht.com social network about their experience using its message board.
Figure 1 illustrates the first question that was asked from users and the answers that were received. $5 \%$ of gohardasht.com members had found using its message board hard and $42 \%$ found it easy to use.

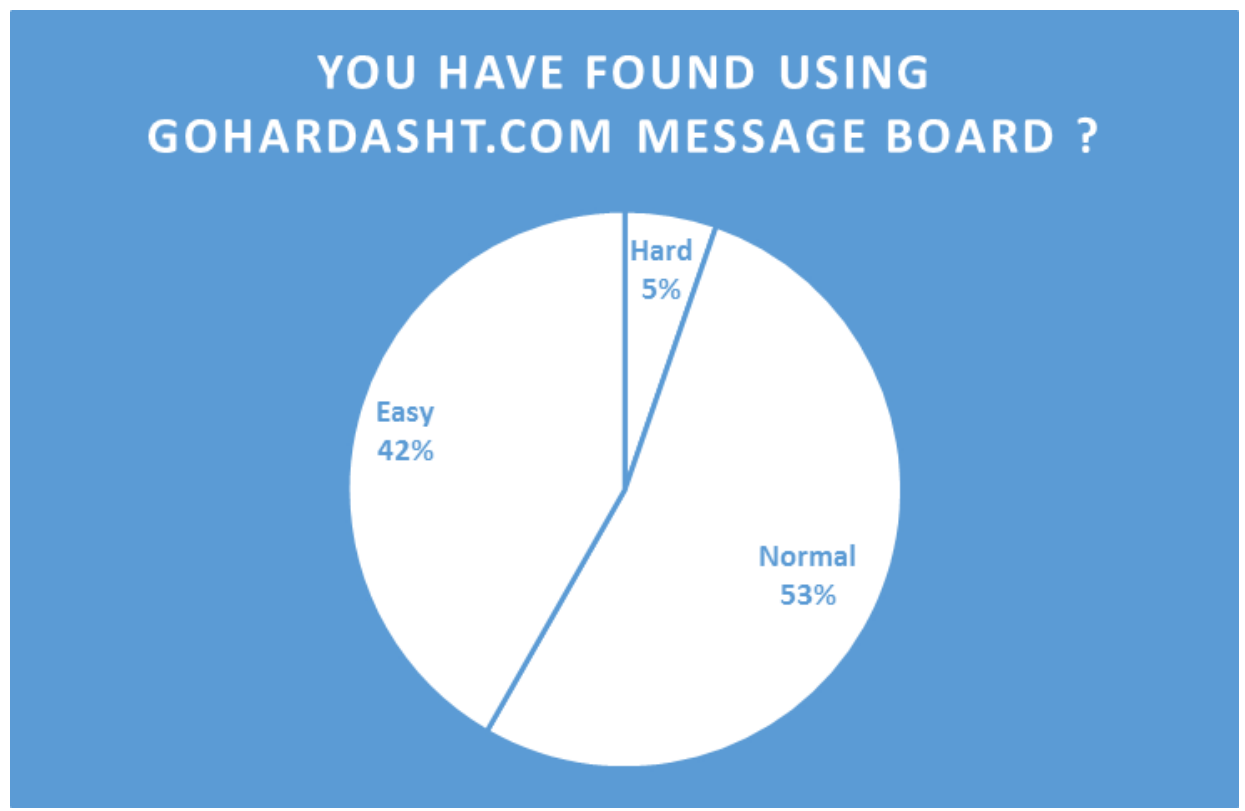

Figure 1: online survey question 1- before implementing proposed framework.

DO YOU FACE ANY DIFFICULTIES

ACCESSING DIFFERENT PART OF THE

GOHARDASHT.COM MESSAGE BOARD?

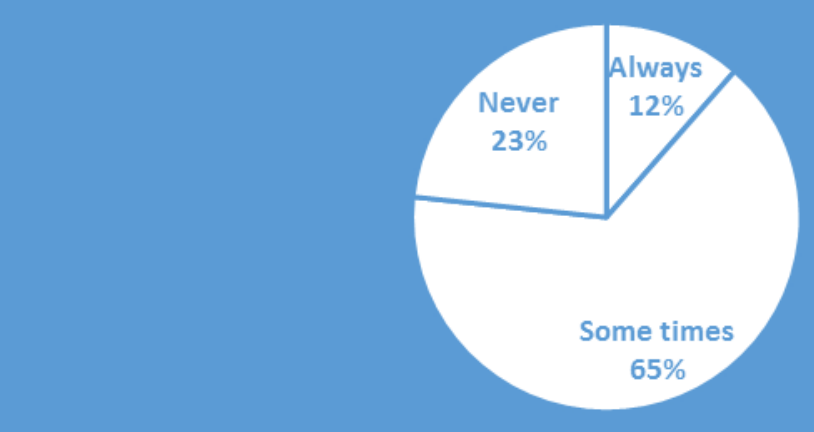

Figure 2: online survey question 2 - before implementing proposed framework.

Figure 2 illustrates second question of the online survey. Only $23 \%$ of gohardasht.com social network members did not have any difficulty accessing different parts of the message board. In contrast $65 \%$ of members sometimes face difficulties and $12 \%$ always have problems accessing different part of the message board. This clearly shows that some enhancement in interaction design must be applied.

\section{Proposed framework}

After performing user profiling and reviewing literatures about interaction design author has suggested a framework to be implemented on interaction design of the websites. Based on this framework following steps must be taken by developers and these questions must be addressed: 
1. Considering mobile, tablet and PC users:

a. How users can interact with the website, if they use small smart phone to browse the web?

b. How users can interact with the website if they use tablets?

c. How users can interact with the website if they use PC?

2. Considering similar websites structures:

a. Is the structure of the website similar to the other (close to the subject) websites?

b. Are the used icons and other metaphors similar to other websites?

c. All the similar icons and metaphors inside the website do the same thing?

3. All Ajax link on the website should answer these three questions :

a. What would be the user experience, if the link was clicked and URL was available?

b. What would be the user experience, if the link clicked and connection was disturbed?

c. What would be the user experience, if the link clicked and the URL was not available?

4. All the actions that users might want to make must answer these questions:

a. Is it clear in every page how to perform a desired action that might or might not be related to this page? b. When an action was successfully performed, will an appropriate feedback be given to the users?

c. If an action failed, would an appropriate feedback be given to the users?

d. If the connection was lost while performing the action, would the state of the users be saved?

e. Are the effects of the action clear to the users?

f. Can users undo the actions they do not want in easy way and receive appropriate feedbacks?

5. Considering Special users:

a. Are blind color users able to use this website?

b. Are foreign users able to use this website?

c. Are people with disability able to use this website?

\section{Second study}

The proposed framework has been implemented in gohardasht.com social network message board section. After implementing this framework to improve the interaction design of the website, another online survey was conducted among users, figure 3 and figure 4 illustrates these findings.

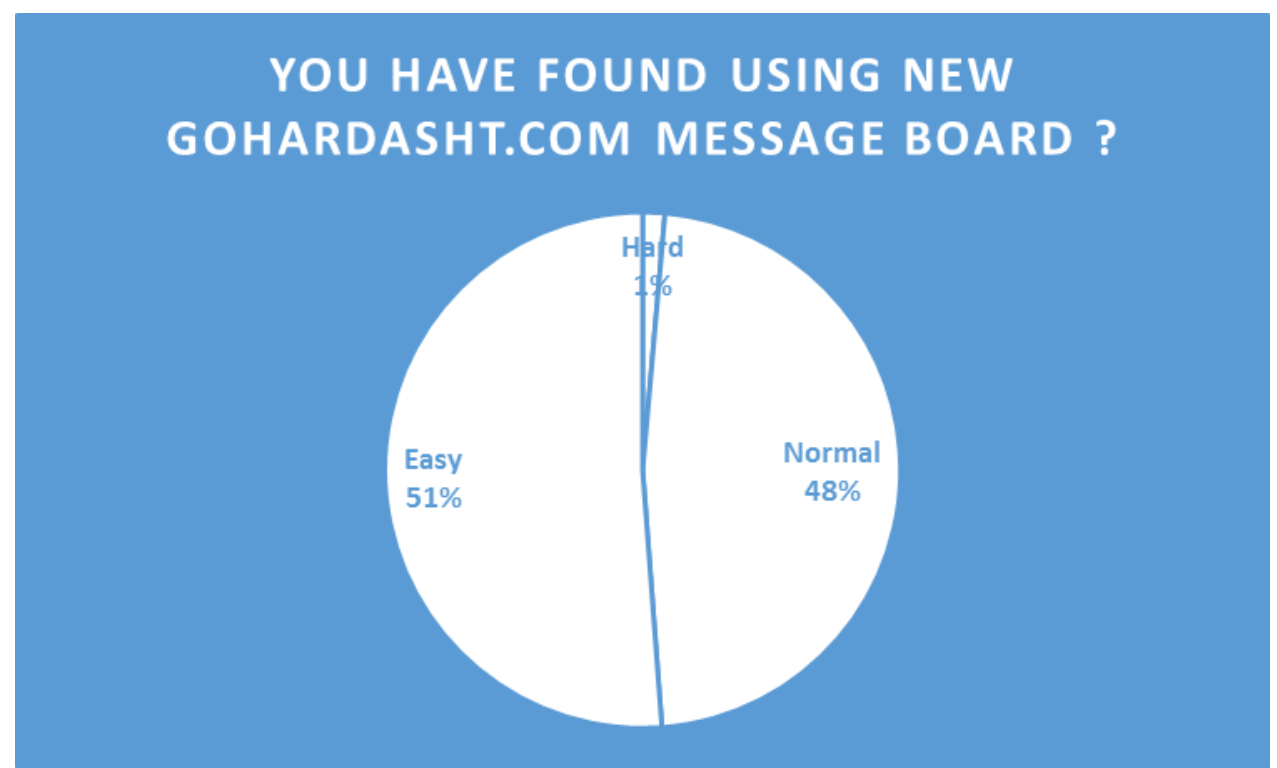

Figure 3: online survey question 1- after implementing proposed framework. 
DO YOU FACE ANY DIFFICULTIES

ACCESSING DIFFERENT PART OF THE

GOHARDASHT.COM MESSAGE BOARD?

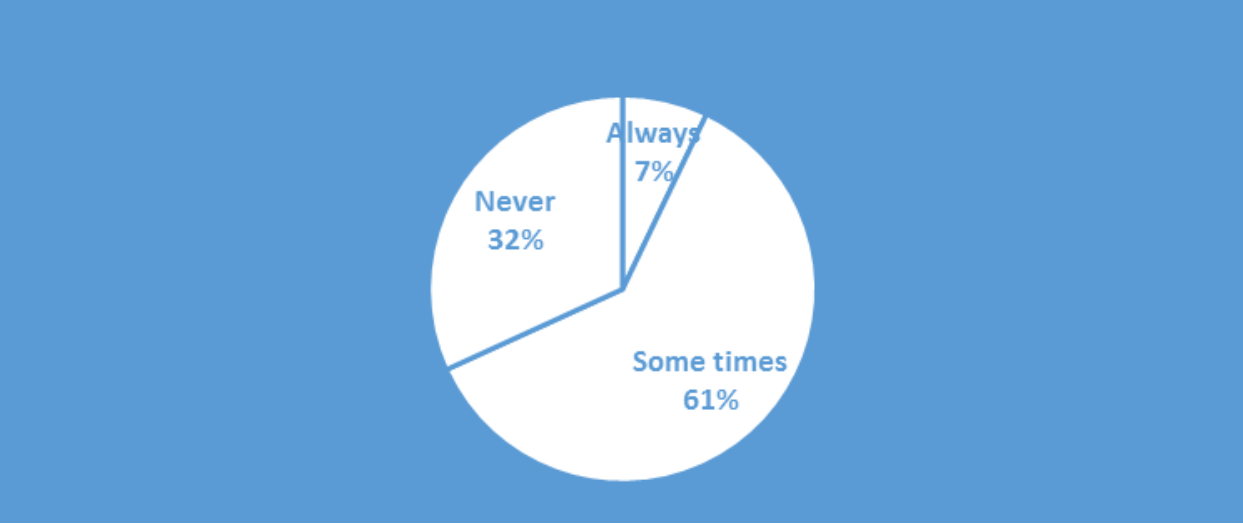

Figure 4: online survey question 2- after implementing proposed framework.

\section{Evaluation}

after implementing proposed framework on gohardasht.com social network website.

Figure 5 illustrates the difference of users' opinions about the webpage design before and

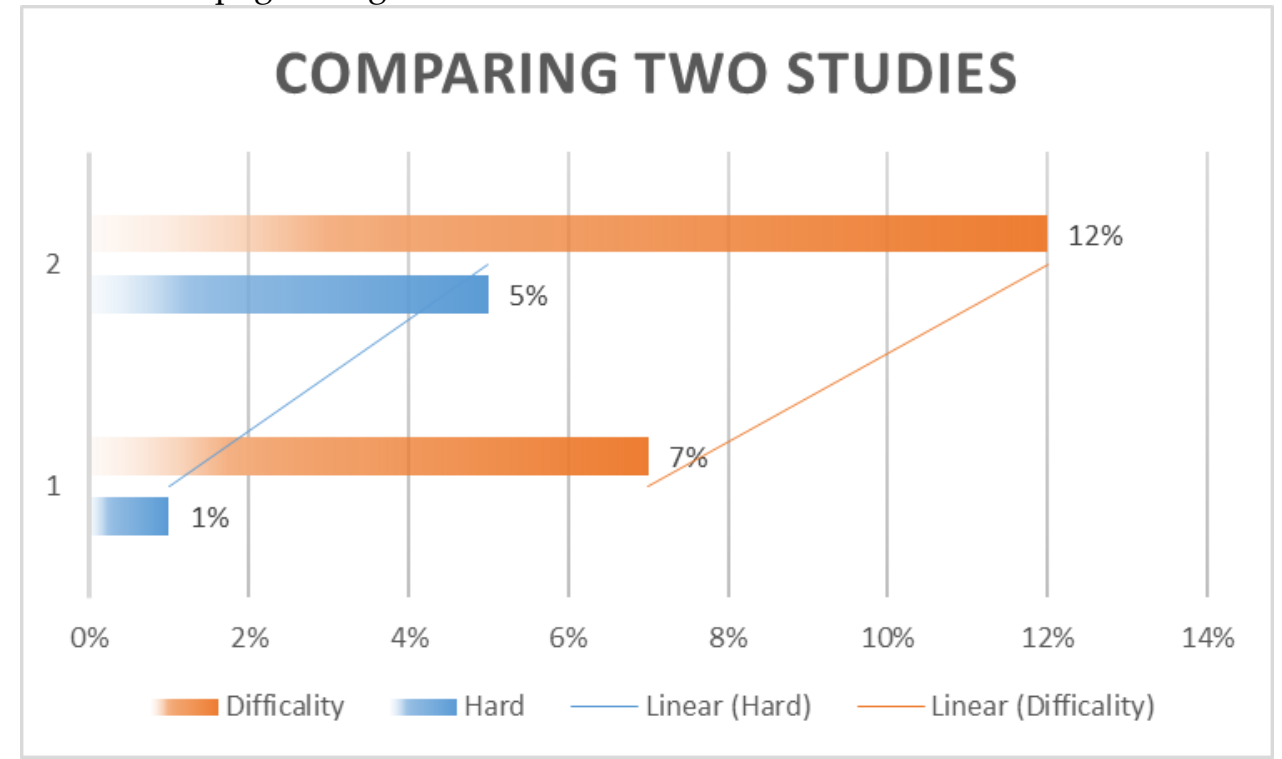

Figure 5: Comparing results of studies before and after implementing framework.

As figure 5 shows, it can be seen after implementing the proposed framework, users feel better about the gohardasht.com message board interaction design. Before implementing the framework, $12 \%$ of gohardasht.com members faced difficulty using message board while after implementing the proposed framework this number was reduced to only $7 \%$. Besides, before implementing the framework $5 \%$ of gohardasht.com members believed it is hard to use message board while after implementing it only $1 \%$ stated that is hard to use that.

\section{Conclusion}

To sum it up in this paper author has proposed a framework to improve the interaction design of modern websites and validate it by performing two studies on interaction design of a social network website called gohardasht.com. To be able to use this framework 5 steps and 18 questions was designed by the author. Based on the findings of two studies implementing this framework for interaction design of websites in web 2 era can 
significantly improve users experience and users satisfaction of the websites.

Moreover other design principles was reviewed in this paper and it was discussed why those principles are not suitable for modern design and why a new framework is needed. Furthermore this proposed framework gives developers a guideline to develop interaction design of websites without interfering with developers taste and style. Hence developers can design whatever they like until they follow these framework structure in their design.

In conclusion it can be understand that by implementing this framework on modern websites, developers can be ensure that users will be more happy. Finally it is suggested to other researchers to perform more research on interaction design of modern websites and continue to update their frameworks to let web developers produce more up to date and exciting websites.

\section{References}

Creswell, J. W. (2002) Educational research: Planning, conducting and evaluating, quantitative.Morgan, S. L. \& Winship, C. (2007) Counterfactuals and causal inference: Methods and principles for social research. Cambridge University Press.

Garrett, Jesse James. "Ajax: A new approach to web applications." (2005): 1-6.

Ivory, Melody Y., and Rodrick Megraw. "Evolution of web site design patterns." ACM Transactions on Information Systems (TOIS) 23.4 (2005): 463-497.

Jeng, J. (2005) Usability assessment of academic digital libraries: effectiveness, efficiency, satisfaction, and learnability. Libri 55(2-3):96121.

Knowles, J. G. \& Cole, A. L. (2008) Handbook of the arts in qualitative research: Perspectives, methodologies, examples, and issues. Sage.

Newman, Mark W., and James A. Landay. "Sitemaps, storyboards, and specifications: a sketch of Web site design practice." Proceedings of the 3rd conference on Designing interactive systems: processes, practices, methods, and techniques. ACM, 2000.
Nielsen, Jakob, and Raluca Budiu. Mobile usability. MITP-Verlags $\mathrm{GmbH} \&$ Co. KG, 2013.

Nielsen, J. (1994a) Enhancing the explanatory power of usability heuristics. In Proceedings of the SIGCHI conference on Human Factors in Computing Systems.) ACM, pp. 152-158.

Preece, Jenny, Helen Sharp, and Yvonne Rogers. Interaction Design-beyond human-computer interaction. John Wiley \& Sons, 2015. 